\title{
Uluslararası Standartlarda İkinci Derece Birinci Sınıf Bir Ulusal Düşey Kontrol Ağının Tesis ve Ölçü Esasları
}

\author{
Servet YAPRAK ${ }^{1 *}$ \\ ${ }^{1}$ Gaziosmanpaşa Üniversitesi, Mühendislik Fakültesi, Harita Mühendisliği Bölümü, Tokat \\ (servet.yaprak@gop.edu.tr) ORCID ID 0000-0001-9593-5201
}

\begin{abstract}
$\ddot{O} \mathbf{z}$
Jeodezinin en önemli görevlerinden biri fiziksel yeryüzü üzerindeki doğal ve yapay detayların üç boyutlu konumsal bilgilerini üretmektir. Yeryüzü üzerindeki konum bilgileri daha önce tesis edilmiş olan yatay ve düşey kontrol noktaları ve Global Navigation Satellite System (GNSS) Ağları ile elde edilir.

Son yıllarda konum bilgilerinin üretilmesinde GNSS alıcılarının kullanımı oldukça yaygınlaşmıştır. Bununla birlikte GNSS sistemlerinden elde edilen yükseklik değeri ölçülen noktanın elipsod normali boyunca referans elipsoidine olan uzaklığını ifade eden elipsoidal yüksekliktir (h). Elipsoidal yükseklik geometrik bir değer olup fiziksel bir karşıllığı yoktur, dolayısı ile gerçek anlamda bir yüksekliği ifade etmez. Bu nedenle mühendislik problemlerimizin ç̧̈zümü için elipsoidal yüksekliklerin (h) ortometrik yüksekliğe (H) dönüştürülmesi gerekmektedir. Ortometrik yükseklik, yeryüzü üzerindeki bir noktanın çekül eğrisi boyunca geoit yüzeyine olan uzaklı̆̆ıdır. GNSS' in etkin kullanımı için hassas bir düşey kontrol ağına ve $\mathrm{cm}$ hassasiyetinde belirlenmiş geoit yüzeyine ihtiyaç vardır. Hassas bir geoit yüzeyi oluşturmak için, öncelikle Uluslararası standartlarda hassas nivelman ağının oluşturulması, yeterli sıklıkta gravite ölçülerinin yapılması, mareograf istasyonlarından ortalama deniz seviyesi verisinin elde edilmesi ve ölçülerin dengelenmesi gerekmektedir.

Bilindiği gibi ülkemize ait mevcut düşey kontrol ağımız (TUDKA) devam eden yol genişletme çalışmaları ve altyapı çalışmaları nedeni ile büyük oranda tahrip olmuştur. Buna ilave olarak bu ağdan elde edilen geoit yüzeylerinin hassasiyeti ancak $\pm 10 \mathrm{~cm}$ civarındadır. Sonuç olarak bizim DKA' mızı yenileme ihtiyacımız ortaya çıkmiştır. Bu nedenle bu çalı̧̧mada Amerikan Federal Geodetic Control Komite (FGCC) Standartları çerçevesinde gerçekleştirilmiş İkici Derece Birinci Sınıf bir ulusal düşey kontrol ağından hareketle Uluslararası ve ulusal DKA' larının tesisi ve nivelman ölçülerinin gerçekleştirilmesinde dikkat edilecek konular açıklanmıştır.
\end{abstract}

Anahtar Kelimeler: Hassas nivelman, geoit, düşey kontrol ăgl

\section{Monumentation and Measurement Principles of the First Order Second Class Vertical Control Network in International Standards}

\begin{abstract}
One of the most important tasks of geodesy is to produce three dimensional spatial information of the natural and artificial details on the physical earth. Location information on the ground is obtained by previously installed horizontal and vertical control points and Global Navigation Satellite System (GNSS) Networks.

In recent years, the use of GNSS receivers has become widespread in generating position information. However, the height value obtained from GNSS systems is the ellipsoidal height (h), which represents the distance of the reference ellipsoid along the ellipsoid normal of the measured point. The ellipsoidal elevation is a geometric
\end{abstract}

\footnotetext{
* Sorumlu Yazar
} 
value and does not have a physical counterpart, so it does not mean a height in real sense. For this reason, we need to convert the ellipsoidal heights $(h)$ to the orthometric height $(\mathrm{H})$ for the solution of our engineering problems. The orthometric height is the distance from the geoid surface along a plumb line of a point on the earth. For effective use of GNSS, there is a need for a sensitive vertical control network and a geoid surface determined in $\mathrm{cm}$ precision. In order to create a sensitive geoid surface, firstly it is necessary to establish a sensitive leveling network in international standards, to make gravity measurements in sufficient frequency, to obtain average sea level data from mareograph stations and to adjustment the measurements.

As is known, our country's current vertical control network (TUDKA) has been destroyed in large scale due to ongoing road expansion work and infrastructure works. In addition, the sensitivity of geoid surfaces obtained from this network is only $\pm 10 \mathrm{~cm}$. As a result, we need to be able to defeat our control network.

For this reason, in this study, issues to be considered in the implementation of the international and national vertical network installation and leveling measures have been explained in the context of a national vertical control network of a Second Degree First Class implemented within the framework of the American Federal Geodetic Control Committee (FGCC) Standards.

Keywords: Precise leveling, geoid, vertical control network

\section{GİRIŞ}

Bilindiği gibi Türkiye Ulusal Düşey Kontrol Ağ1 (TUDKA-99) 1970-1993 yıllar1 arasında ölçülen 151 adet I. derece ve 41 adet II. derece geçki ile, 1970 yılından önce ölçülen 7 adet I. derece ve 44 adet II. derece geçki olmak üzere toplam $29316 \mathrm{~km}$ uzunluğunda, 25680 noktadan oluşmaktadır (Ayhan ve Demir,1999). 1999 Marmara depreminden sonra 2002 y1lında bölgeye ait $1300 \mathrm{~km}$ uzunluğunda 14 Adet I ve II nci derece geçki ölçüsü yeniden ölçülmüştür (Demir, 1999). Ülkemizde yükseklik sistemi olarak ortometrik yükseklik kullanılmaktadır. Ülkemizde GNSS alıcısı kullanıcısı her geçen gün artmaktadır. HGK 1992 de TG92, 1999 da TG99 ve TG99A geoit modelleri üretmiştir. En son 2009 yılında 2009 y1linda TGH-09 hibrit geoit modeli üretirmiş olup modelin doğruluğu $\pm 8 \mathrm{~cm}$ dir (URL.1). Ancak gravite verilerinin seyrek olduğu dağlık bölgelerde ve sinır sulak alanlarda bu doğruluk daha da düşmektedir (K1liçoğlu vd., 2011, Simav vd, 2015). Türkiye geneli düşünüldüğünde H.G.K.lığının bu güne kadar hesapladığı hibrit jeoit modellerinin dış doğrulukları $\pm 10 \mathrm{~cm}$ 'den daha iyi değildir. 2011 yılında TUDKA'nın yaklaşık 10.000 km'lik kısmında yapılan çalışma sonucunda noktaların \%63'lük kısmının tahrip olduğu saptanmıştır (URL.1). Ülkemizde kullanıcıların 2-3 cm doğruluğunda ortometrik yükseklik bilgisine ulaşmak bu ağla mümkün değildir. $\mathrm{Bu}$ nedenle Türkiye Yükseklik Sisteminin Modernizasyonu Projesi başlatılmıştır. $\mathrm{Bu}$ çalışmada gerçekleştirilmiş olan ve yöneticiliğini yapmış olduğum Suudi
Arabistan Hassas Nivelman A $\breve{g} 1$ Projesinin iki etabında edinmiş olduğum deneyimlerle birleştirerek Uluslararası kullanımda olan FGCC uluslar arası ve ulusal hassas nivelman ağlarının tesis ve ölçüleri ile ilgili önemli konular açıklanmıştır.

Düşey Kontrol Ağ1 projeleri, nokta yerlerinin standartlara uygun seçimi, noktaların tesisi, nivelman ölçülerinin gerçekleştirilmesi ve ölçülerin dengelenmesi olmak üzere dört aşamadan oluşmaktadır.

\section{Nokta yerlerinin seçimi;}

Düşey Kontrol Ağı Noktaları yalnızca Ulusal Jeodezik Düşey Ağın bir parçası olarak görülmekle birlikte bu noktalar uluslararası standartlarda bir hassasiyete ve kalıcılığa sahip olmalıdır. Çünkü bu noktalar, yerkabuğu üzerinde üç boyutlu konumları hassas olarak bilinen ve uzun süre kalıcı olması gereken noktalardır. Bu nedenle nokta yerleri seçilirken özellikle sağlam zeminler ve az hasar görecek kalıcı yerler seçilmeye çalışılmalıdır (URL.2). Ayrıca bu noktalar her türlü mühendislik yapısına altık oluşturacağı için uluslar arası standartlarda hassasiyetle tesis edilmelidirler. FGCC bu nedenle yükseklik ağlarının genel olarak ulusal karayolu ve demiryolu hatlarını takip etmesini ve buralara tesis edilecek noktaların Şekil 1 de görüldüğ̈̈ gibi belirlenen standartlarda yere korezyona uğramayacak çelik çubukların çakılması ile (Tip 1) tesisini önermektedir. Eğer güzergahlara yakın büyük kaya kütleri varsa zemin işaretinin Tip 2 olarak 
kaya gövdeye tesisini önermektedir (Simith, 2010).

Kalıcı bir DKA oluşturmak için ilk yapılması gereken nokta yerlerinin uluslar aras1 standartları sağlayacak özellikler gözetilerek seçimidir. BM noktalarının tesis edileceği yerler önce USA National Geodetic Survey (NGS) yönetmeliğinde belirtilen şartlara uygun olarak sayısal bir altlık harita üzerinde işaretlenir. Haritada işaretlenen bu noktaların yerleri arazide gezilerek zemin yapisı ve uygunluk yönünden kontrol edilir.

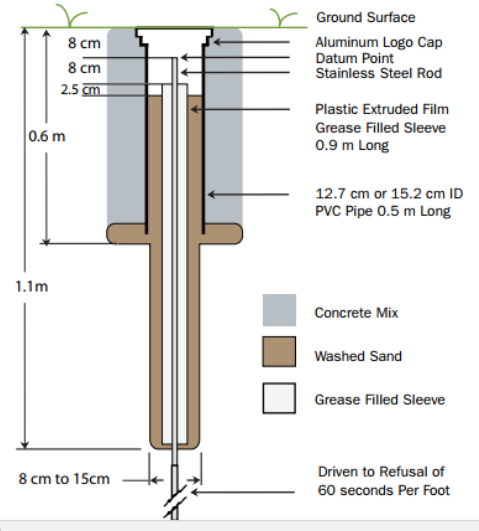

Şekil 1. NGS Tip 1 nivelman noktası (Simith, 2010)

Nokta yerleri zemin tesisinde sorun yaşanmaması için yeraltından enerji hattı, boru hattı benzeri tesisin varlığ edilmeli ve yerel idarelerden gelecek yatırımlarla ilgili bilgi alınmalıdır. Bu şartları sağlayan yerlere rastlayan yerler nokta yeri olarak seçilebilir. NGS nokta yerlerinin seçimi için Tablo 1 de istenilen özelliklere sahip olacak șekilde noktalar arası mesafelerin

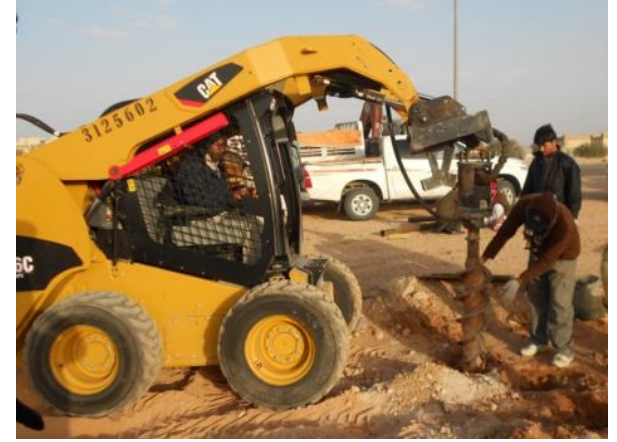

Şekil 2. Nivelman noktası çukurunun iş makinası ile açılması

Açılan çukur temizlendikten sonra $24.2 \mathrm{~mm}$ çapında yivli paslanmaz çelik çubuk Şekil 3a maksimum $3.0 \mathrm{~km}$ ve min $1.6 \mathrm{~km}$ aralığında olmasını öngörmektedir. Bu çerçevede nokta yerleri bu mesafeler gözetilerek karayolu ve demiryolu hatları boyunca seçilip geçici olarak işaretlenir.

Seçilen noktanın konumu el GNSS alıcısı ile kaydedilmeli ve kuzey, güney, doğu ve batı yönlerden etrafın fotoğrafları çekilerek önceden hazırlanmıș bir formatta "nokta tanımlama kartı" hazırlanmalıdır. Bu kart daha sonra noktayı tesis edecek ekipler tarafindan kullanılacağı için noktanın tekrar bulunması konusunda görüntü ve açıklamalarla net bilgiler içermelidir. $\mathrm{Bu}$ amaçla hazırlanmış olan Android ve IOS işletim sistemleri ile uyumlu cep telefonları üzerinden kullanılan yazılımlar da mevcuttur. Açık uçlu bu yazılımlarla istediğiniz değişiklikleri yapmak sureti ile arazide ekiplerin seçmiş oldukları noktanın yerini yönetici olarak anında görme, kontrol etme, onaylama veya reddetme olanağına da sahip olunabilmektedir. Ayrıca yazılım kontrol kurumuna da açılarak kontrol mühendisinin onay işlemleri de online olarak zaman kaybetmeden yürütülebilmektedir.

\section{NOKTALARIN APLIKASYONU}

Nokta yerlerinin onaylanması aşamasından sonra noktaların araziye aplikasyonu aşamasına geçilir. Nokta aplikasyonları kaya blokların olduğu yerler (Tip 2), bu yerler dışında NGS Tip 1olarak aplike edilir (Simith, 2010). Şekil 2 de görüldüğü gibi seçilmiș olan nokta yeri $30 \mathrm{~cm}$ çapında $60 \mathrm{~cm}$ derinliğinde spiral delici iş makinesi ile açılır.

ve $3 b$ de görüldüğü gibi ucuna özel hazırlanmış ok takılarak açılan çukurun merkezine çakılmak üzere hazırlanır.

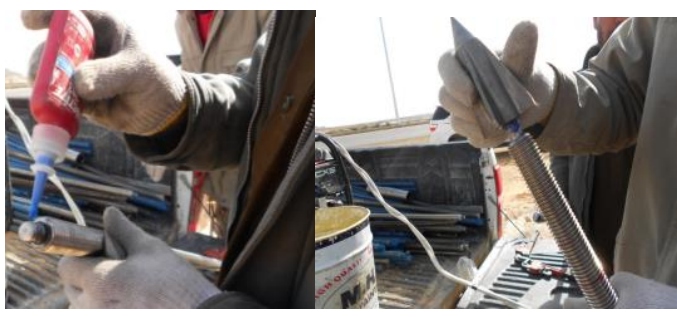

Şakil 3(a,b). Nivelman noktasına (Tip 1) çakılacak okun hazırlanması 
1 ve $2 \mathrm{~m}$ boylarında hazırlanmış çubuklar elektrikli çekiçle 5 dakika süre ile dikey olarak çakılır (Şekil 4 a, 4b). Çakma işleminin başlama ve bitiş süreleri ile çakılan çubuk uzunluğu kaydedilir. Bundan sonra her bir dakika için çakma işlemi 1 dakikada $20 \mathrm{~cm}$ girinceye kadar sürdürülür. Bir dakikalık çakma süresinde $20 \mathrm{~cm}$ den az gidilebiliyorsa çakma işlemi sonlandırılır. Her bir dakikada ve toplamda çakılan çubuk boyu kaydedilerek ekip şefi ve kontrol elemanı tarafindan form imzalanır.

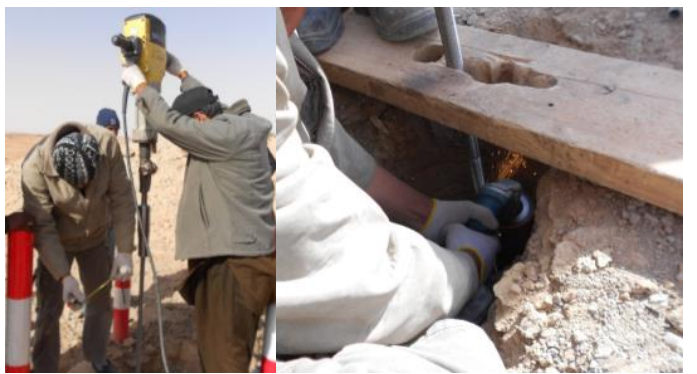

Şekil 4(a,b). Nivelman nokta cubuğunun çakılması ve sonlandırılması

Çakılan çubuk yüzeyden yaklaşı $45 \mathrm{~cm}$ aşağıdan elektrikli testere ile kesilir (Şekil 5a). Kesilen uç düzeltildikten sonra uygun bir somun kullanılarak kesilen uca $40 \mathrm{~cm}$ lik datum noktası ilave edilir. Datum noktası ile çakılan çubuğun birleşim yeri kaynak makinesi ile ve güçlü yapıştırıcı ile sağlamlaştırılır. Çelik çubuğun düşeyliği kontrol edilir (Şekil $5 b)$.

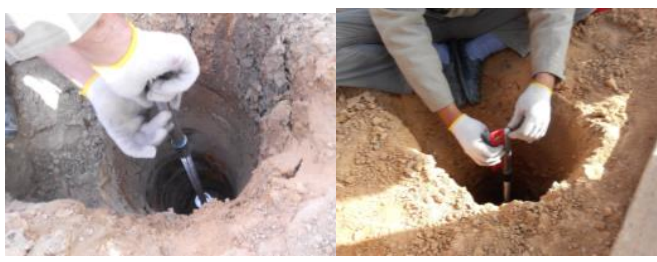

Şekil 5 (a,b). Nivelman noktasına datum noktasının eklenmesi

Hazırlanmış olan $0.9 \mathrm{~m}$ boyunda ve $5 \mathrm{~cm}$ çapında PVC boru üzerine datum noktası eklenmiş olan çubuğa geçirilir. PVC borunun yere iyice teması sağlanır ve PVC borunun içine paslanmayı önleyici gres yağı doldurulur (Şekil 6a). PVC boru ile datum noktası arası paslanmaz çelik kapakla şekilde görüldüğü gibi kapatılır (SSekil 6b). Nivelman noktasının düşeyliği kontrol edilerek çukurun tabanına 30 cm yüksekliğinde yüksek dozlu, çabuk kuruyan çimento dökülerek nivelman noktasının hareketi önlenir.

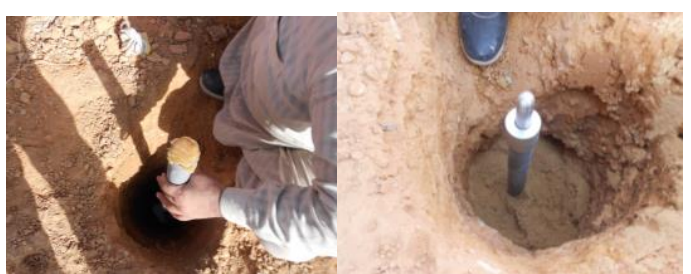

Şekil 6(a,b). PVC borunun gres yağ doldurulması ve kapatılması

PVC boru içine gres doldurularak korumaya alınmış olan nivelman noktası bu kez $15 \mathrm{~cm}$ çapında $60 \mathrm{~cm}$ boyunda ikinci bir PVC boru ile korumaya alınır. Daha önce hazırlanmış olan nivelman noktası bu kez $15 \mathrm{~cm}$ lik PVC borunun ortasına gelecek şekilde yerleștirilir. İki PVC arası hazırlanmış olan ince kumla doldurularak koruyucu kapak geçirilir (Şekil 7a). Dıştaki PVC ile kazılan çukur arasındaki boşluk zemin düzeyine kadar betonla doldurulur. Dıştaki PVC ye takılmış olan kapağın yataylığı da kontrol edilerek çimentonun donması beklenir (Şekil 7b). Bu arada en üstte kalacak nivelman noktasının paslanmaz nokta numarası yazılarak diş kapağa monte edilir Şekil 7c, d). Etrafta çimento ve toprak artıkları düzeltilir.

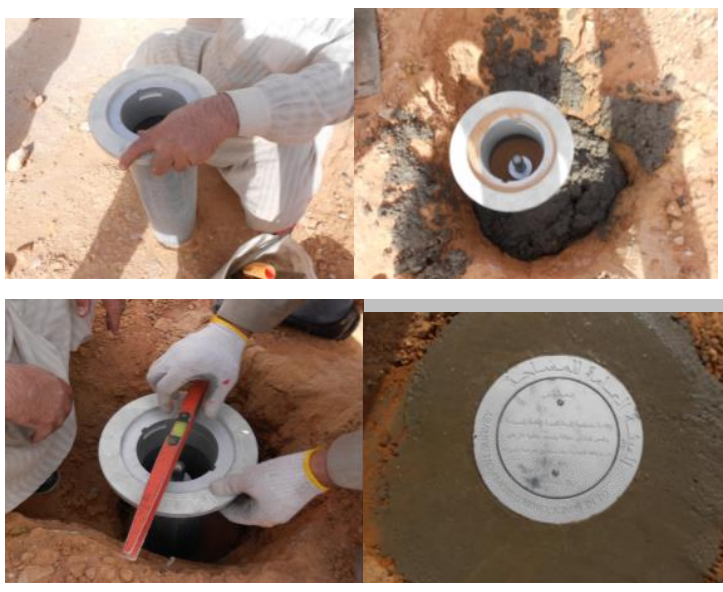

Şekil 7(a,b,c,d). Diș PVC borunun hazırlanması, Dış PVC borunun yerleştirilmesi, Tesis işleminin tamamlanması.

Her nokta için kuzey, güney, doğu ve batı yönlerinde arkada silüet görünecek şekilde ve tepeden kapak üzerindeki nokta numaras1 okunacak şekilde dijital resimler çekilir. Yapılan işlemin uygunluğu arazideki uygulama ekibi ve kontrol mühendisi tarafindan imzalanarak aplikasyon işlemi tamamlanmış 
olur. Noktanın keşifteki yeri herhangi bir nedenle değișmișse noktanın yeni koordinatları ve değişim nedeni tutanağa yazılır. Nokta konum bilgilerinin $\pm 3 \mathrm{~m}$ hassasiyetle kaydedilmesi daha sonra dengelemede kullanılacağı için önemlidir. Eğer Fulcram (URL. 3) türü online yazılım kullanılıyorsa bu işlemlerin hepsi yüksek çözünülürlüklü bir cep telefonu ile de gerçekleştirilebilir. Hazırlanmış olan bu verilerle (noktanın konumu, her yönden çekilmiş fotoğrafları, tesis noktasının özellikleri ve konumunu tanımlayan bilgiler) her nokta için nokta tanımlama kartı "Description Card" hazırlanır. NGS bu kartın kendi sitesinde mevcut olan WINDESC yazılımı ile hazırlanmasını önermektedir (URL. 4).

Eğer hat üzerinde tespit edilen mesafelerde \pm 200 m yakınlarda büyük kütleli tek parça kaya veya köprü viyadük gibi yüksek dozlu betondan yapılmış bir tesis varsa bivelman noktasi bu kütlenin uygun yerine $20-25 \mathrm{~cm}$ uzunluk ve $3 \mathrm{~cm}$ çapında karot makinası ile yer açılarak da tesis edilebilir. Açılan karot deliği kuvvetli bir epoksi ile doldurularak Şekil 8 de görülen Tip 2 nivelman noktası, tepesi yüzeyde kalacak şekilde yerine oturtulur.

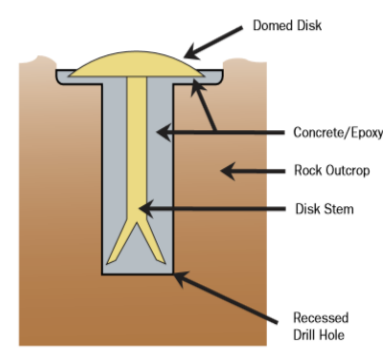

Şekil 8. Tip 2 nivelman noktası (Simith, 2010)

$\mathrm{Bu}$ iki tip kalıcı nokta dışında yine yönetmeliğe göre yaklaşık $1.6 \mathrm{~km}$ aralıklarla geçici noktalar (TBM) tesis edilmelidir. $\mathrm{Bu}$ noktalar gidiş dönüş nivelman ölülerinde kullanılmak üzere tesis edilir. $\mathrm{Bu}$ amaçla nivelman ekiplerine $10 \mathrm{~mm}$ çapında $20-30 \mathrm{~cm}$ uzunluğunda ucu sivriltilmiş çelik çubuklar verilir. $\mathrm{Bu}$ çubuklar nivelman öncesi bir eleman tarafindan mesafeler tekerlekli metrelerle kontrol edilerek çakılabilir.

\section{NIVELMAN ÖLÇÜLERİ}

Uluslar arası ve ulusal DKA'larının NOAA Manual NOS ve Geodetic Levelling and
Federal Geodetic Control Committee Standards and Specifications for Geodetic Control Networks (FGCC) (URL.5) standartlarına göre yürütülmesi öngörülmüştür. $\mathrm{Bu}$ standartlar çerçevesinde kullanılacak donam özellikleri ve ölçü yöntemleri kısaca aşağıdaki tabloda özetlenmiştir. Bu şartnameye göre DKA ölçülerinde kullanılacak aletler kompansatörlü veya eğim vidalı nivolar olmalıdır. Kullanılacak nivelman miraları tek parçalı ve invar mira olmalıdır. Yalnız ikinci derece birinci ve ikinci sınıf noktalar veya ağların ölçüsünde tek ölçekli miralar kullanılabilir. Üçüncü derece ağlar için ahşap veya metal miralar kullanılabilmektedir.

Mira altlığı olarak arazi yumuşak ise çelik dönüş çivisi, arazi sert ise $7 \mathrm{~kg}$ lık mira altlığ önerilmektedir. Miralarda bir göz hizasında, diğeri tabanda olmak üzere iki küresel düzeçli olmalıdır gibi standartlar bulunmakta olup DKA' ları için önerilen standartlar aşağıdaki tabloda özetlenmiştir.

Nivelman ölçüleri her ekip beş kişiden oluşan beş ile on ekip tarafından gerçekleştirilmiştir. Projede nivelman ölçüleri ölçme hassasiyeti $0.3 \mathrm{~mm} / \mathrm{km}$ olan Trimble DI03 sayisal nivo ve tek parçalı bar kodlu Nedo invar miralar ile gerçekleştirilmiştir. Sicaklık okumaları için \pm $0.03^{\circ} \mathrm{C}$ duyarlıklı üçlü Dostman P755 Dijital termometre seti kullanılmıştır (Şekil 9). Nivo sehpası olarak tek parça sabit bacak uzunluklu sehpa kullanılmıştır.

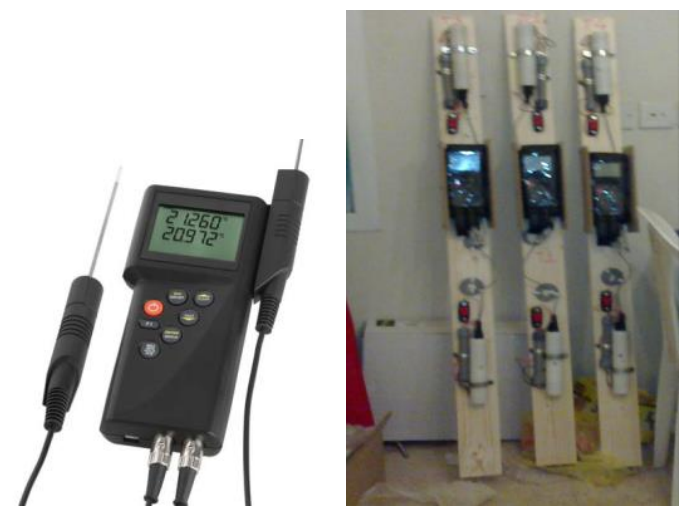

Şekil 9. P755 Dijital termometre ve termometre seti (Demir ve Yaprak, 2015)

Her sabah ölçüye kolimasyon ölçüleri Kukkumaki yöntemi ile kontrol edilerek başlanmaktadır (URL.5). Her aletin günlük kolimasyon değeri dengeleme aşamasında kolimasyon düzeltmesinde kullanılmak üzere 
kaydedilmiştir.. $0.05 \mathrm{~mm} / \mathrm{m}$ sınırını aşan nivo peryodik kalibrasyon dışında kalibrasyona gönderilmiştir. Şekil 10 da nivelman ölçü ekibi ekipmanları ile birlikte görülmektedir.

Tablo 1. Federal Jeodezik Kontrol Komitesi (FGCC) Jeodezik Kontrol Ağları için standartlar ve koşullar (URL.5)

\begin{tabular}{|c|c|c|c|c|c|c|}
\hline \multirow{2}{*}{\multicolumn{2}{|c|}{$\begin{array}{c}\text { Derece } \\
\text { Sinıf }\end{array}$}} & \multicolumn{2}{|c|}{$\mathbf{I}$} & \multicolumn{2}{|c|}{ II } & \multirow{2}{*}{ III } \\
\hline & & I & II & $\mathbf{I}$ & II & \\
\hline \multicolumn{7}{|c|}{ Nivoların özellikleri } \\
\hline \multicolumn{2}{|c|}{$\begin{array}{l}\text { Gözlem ekseninin } \\
\text { hassasiyeti }\end{array}$} & $0,25^{\prime}$ & $0,25^{\prime}$ & $0,50^{‘}$ & $0,50^{‘}$ & $1,00^{\prime}$ \\
\hline \multicolumn{2}{|c|}{$\begin{array}{l}\text { Minimum okuma } \\
\text { hassasiyeti (mm) }\end{array}$} & 0,1 & 0,1 & $0,5-1,0$ & 1,0 & 1,0 \\
\hline \multicolumn{2}{|c|}{$\begin{array}{l}\text { Maksimum kolimasyon } \\
\text { hatası } \mathbf{m m} / \mathbf{m}\end{array}$} & 0,05 & 0,05 & 0,05 & 0,05 & 0,10 \\
\hline \multicolumn{2}{|c|}{$\begin{array}{l}\text { Kolimasyon hatası test } \\
\text { minimum aralığı (gün) }\end{array}$} & 1 & 1 & 1 & 1 & 1 \\
\hline \multicolumn{2}{|c|}{$\begin{array}{l}\text { Maksimum gözlem } \\
\text { mesafesi (m) }\end{array}$} & 50 & 60 & 60 & 70 & 90 \\
\hline \multicolumn{7}{|c|}{ Miraların Özellikleri } \\
\hline \multicolumn{2}{|c|}{ Miranın özelliği } & $\begin{array}{l}\text { İnvar \& Çift } \\
\text { ölçekli }\end{array}$ & $\begin{array}{l}\text { İnvar \& Çift } \\
\text { ölçekli }\end{array}$ & $\begin{array}{l}\text { İnvar \& Çift } \\
\text { ölçekli/Tek } \\
\text { ölçekli }\end{array}$ & $\begin{array}{l}\text { İnvar \& Tek } \\
\quad \text { ölçekli }\end{array}$ & $\begin{array}{l}\text { Ahşap veya } \\
\text { metal }\end{array}$ \\
\hline \multicolumn{2}{|c|}{$\begin{array}{c}\text { Mira kalibrasyon aralığı } \\
\text { (yıl) }\end{array}$} & 1 & 1 & - & - & - \\
\hline \multicolumn{2}{|c|}{$\begin{array}{l}\text { Mira düzeci düşey } \\
\text { hassasiyeti }\end{array}$} & $10^{\prime}$ & $10^{\prime}$ & $10^{\prime}$ & $10^{\prime}$ & $10^{\prime}$ \\
\hline \multirow{3}{*}{\multicolumn{2}{|c|}{ Mira okuma düzeni }} & $\begin{array}{l}\text { Tek gidiş ve } \\
\text { çift okuma } \\
\text { veya }\end{array}$ & $\begin{array}{l}\text { Tek gidiş ve } \\
\text { çift okuma } \\
\text { veya }\end{array}$ & $\begin{array}{l}\text { Tek gidiş ve } \\
\text { çift okuma } \\
\text { veya }\end{array}$ & $\begin{array}{l}\text { Tek gidiş ve } \\
\text { çift okuma } \\
\text { veya }\end{array}$ & $\begin{array}{l}\text { Tek gidiş ve } \\
\text { çift okuma } \\
\text { veya }\end{array}$ \\
\hline & & Gidiş/Dönüş & Gidiş/Dönüş & Gidiş/Dönüş & Gidiş/Dönüş & Gidiş/Dönüş \\
\hline & & \multicolumn{4}{|c|}{ Nivelman ölçülerde istenen hassasiyet } & \\
\hline \multirow{2}{*}{$\begin{array}{c}\text { Mira } \\
\text { okuma } \\
\text { mesafe } \\
\text { farkları }\end{array}$} & $\begin{array}{c}\text { Geri-İleri } \\
\text { maksimum } \\
\text { mesafe } \\
\text { farki (m) }\end{array}$ & 2 & 5 & 5 & 10 & 10 \\
\hline & $\begin{array}{c}\text { Geri-İleri } \\
\text { maksimum } \\
\text { mesafe } \\
\text { farkı }\end{array}$ & 4 & 10 & 10 & 10 & 10 \\
\hline \multicolumn{2}{|c|}{$\begin{array}{l}\text { Maksimum bölüm } \\
\text { kapanma hatası (mm) }\end{array}$} & $3 \sqrt{ } \mathrm{D}$ & $4 \sqrt{D}$ & $6 \sqrt{D}$ & $8 \sqrt{ } \mathrm{D}$ & $12 \sqrt{ } \mathrm{D}$ \\
\hline \multicolumn{2}{|c|}{$\begin{array}{c}\text { Maksimum loop } \\
\text { kapanma hatası (mm) }\end{array}$} & $4 \sqrt{ } \mathrm{E}$ & $5 \sqrt{\mathrm{E}}$ & $6 \sqrt{\mathrm{E}}$ & $8 \sqrt{\mathrm{E}}$ & $12 \sqrt{\mathrm{E}}$ \\
\hline
\end{tabular}


Burada;

D: İki nokta arasındaki mesafeyi $(\mathrm{km})$,

E: Loop mesafesini $(\mathrm{km})$ ifade etmektedir.

Çift Okuma: Nivo kurulup düzeçlendikten sonra geri ve ileri mira okumaları gerçekleştirilir. Daha sonra nivo yerinden kaldırılarak düzeci bozulur. Yeniden düzeçlenerek tekrar geri ve ileri okumalar gerçekleştirilir.

Tek Gidiş: Tek gidiş okumasında nivo iki miranın ortasına kurulur ve düzeçlenir. Geri ${ }_{1-}^{-}$ İleri ${ }_{1}+$ İleri ${ }_{2}-$ Geri $_{2}$ okumaları yapılır.

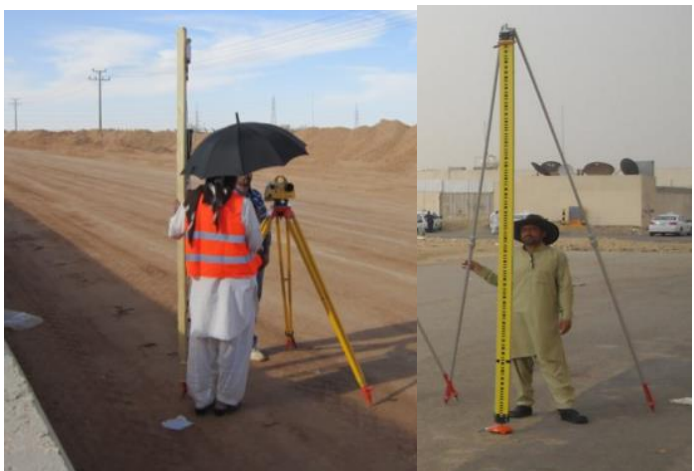

Şekil 10. Ninelman ölçü ekibi ve ekipmanları

Nivelman ölçülerinde FGCC NGS startlarına uyularak aşağıdaki temel kurallar uygulanmıştır.

- Her ileri nivo okumasinda refraksiyon ve sıcaklık düzeltmeleri için eşzamanlı olarak yerden $(0.5,1.5$ ve $2.5 \mathrm{~m})$ yüksekliklerde üç sıcaklık okuması gerçekleştirilmiştir.

- İleri ve geri okumalar arasında yapılan sıcaklık okumaları dijital olarak kaydedilmiştir.

- Projede kullanılan nivolar altı ay, miralar iki y1l ve sıcaklık ölçerler y1llık kalibrasyon uygulamasına tabi tutulmuştur.

- Nivelman ölçülerinde 0.5-metre altında ve $2.5 \mathrm{~m}$ üstünde yapılan mira ölçüleri reddedilmiştir.

- Ölçüler nivoyu güneşin etkisinden korumak için ölçü süresince şemsiye altında yürütülmüştür.

- Nivelman ölçüleri refraksiyon etkisini minimuma indirebilmek için sabah güneşin doğuşundan bir saat sonra başlatılmış ve güneşin batışına bir saat kala ölçüler sonlandırılmıştır.

- Ölçüler aynı gün gidiş dönüş olacak şekilde çift yönlü olarak gerçekleştirilmiştir.

- Ölçü süresince üçlü termometre setinde $\mathrm{t}_{0.5}>\mathrm{t}_{1.5}>\mathrm{t}_{2.5} \quad$ şartının sağlanıp sağlanmadığ kontrol edilmiştir.

- Her ileri veya geri okuma otomatik olarak üç okumanın ortalaması ile elde edilmiştir. Üç okumanın standart sapmasının 0.01 mm sınırında olması istenmiştir.

- Kolimasyon ve küresellik etkisini minimuma indirmek için $50 \mathrm{~m}$ den uzak mira okumasına izin verilmemiştir.

- Geri ve ileri okumalar arasındaki mesafe farkını maksimum 5 metre, hatta toplam geri ileri mesafe farklarının $10 \mathrm{~m}$ yi geçmemesi kontrol edilmiş, sınırı aşan ölçüler yenilenmiştir.

- Geri ve ileri okumalarda mesafelerin eşit olması için mesafeler tekerlekli metre ile kontrol edilmiştir.

- Mira altlığ1 olarak $7 \quad \mathrm{~kg}$ lik $\quad$ NGS standartlarında küresel altlık kullanılmıştır.

- Miralarda biri göz hizasında diğeri aşağıda olmak üzere iki düzeç kullanılmıştır. Mira düzelerinin maksimum $10^{\prime}$ düşey sınırlar içinde olması sağlanmıştır.

- Miraları dik tutabilmek için mekanik düzeçleme aparatı (holder) kullanılmıştır.

- Günlük ölçüler iki nüsha olarak gün sonunda kontrol mühendisine ve merkez ofise kontrol amacı ile gönderilmiştir.

- Günlük ölçülerde $6 \sqrt{D}$ ve yukarıda sıralanan sınır değerleri aşan ölçüler varsa yenilenmiştir. Her hatta ait ölçü bittiğinde $6 \sqrt{D}$ sinırı ve her loop bittiğinde $6 \sqrt{ } \mathrm{E}$ sınırları kontrol edilmiştir.

Her hattın ölçüsü sonlandıktan sonra ölçüler TRANSLEV yazılımında prosess edilmiştir. $\mathrm{Bu}$ program, dijital nivelman ölçü verilerini düzenleme, biçimlendirme ve kontrol etmek için NOAA sitesinden serbest erişimli yüklenip kullanılbilen bir programdır (URL 7). Yapılmış olan nivelman ölçülerinin sıcakl1k farkl111kları, refraksiyon düzeltmeleri 
ve mira düzeltmeleri ve gibi pek çok yerleşik işlev içermektedir. * .lvl dosyalarını ve VERTOBS dosyalarını düzenleme rutinleri de yazılıma dahil edilmiştir. https://www.ngs.noaa.gov/PC_PROD/pc_pro d.shtml\#Translev sayfasından ulaşabilirsiniz.

Projedeki loopların ölçüleri kontrol edilip loop kapanmalarının hata sınırları içinde olup olmadığı kontrol edilmiştir. Projeye ilişkin ölçüler ve ön kontrollerin tamamlanmasından sonra ikinci prosess aşamasına geçilerek nivelman ölçülerine aşağıdaki düzeltmeler getirilmiştir (URL.2).

- Gravite etkisi veya ortometrik düzeltme

- Mira ölçek düzeltmesi

- Invar mira sicaklık düzeltmesi

- Refraksiyon düzeltmesi: 6" hassasiyetle enlem boylam değeri veya yerden $0,5 \mathrm{~m}$ ve 2,5 m yüksekliklerden alınan sicaklık değeri farkları ile

- Manyetik alan ve yer dalgası düzeltmesi

- Kolimasyon hatasi

- Yerkabuğu hareketi düzeltmesi

Bundan sonraki aşama dengeleme aşamasıdır. $\mathrm{Bu}$ çalışmada Ulusal Düşey Kontrol Ağ noktalarının tesisi ve ölçülerin NGS standartlarında yapılamasına ait ana ilkeler uygulama projesinden örnekle açıklanmıştır.

\section{DÜZELTMELER VE HESAPLAR}

$\mathrm{Bu}$ çalışmada sözkonusu olan ağ herbiri 5000 km-7000 km uzunluklarında beş bölgeye bölünmüş olan bir ağ 1 ifade etmektedir. Düşey control ağı doğuda İran Körfezi'nde beș, Kızlldeniz'de yedi olmak üzere toplam oniki adet mereograf istasyonuna bağlanmaktadır. Projenin ilk dört etep geometric nivelman ölçüleri tamamlanmış, beşinci etap ölçüler ve gravite ölçüleri devam etmektedir. Bu nedenle ağ bütünü ile dengelenmemiştir. Ancak her etapta yapılan ölçülere üçüncü bölümde sözedilimiş olan düzeltmeler getirilerek loop kapanmaları control edilmiştir. Ayrıca her etab bir noktanın ortometrik yüksekliği sabit alınarak dengelenmiş ancak projenin bütünü nihai olarak dengelenmemiştir.

$\mathrm{Bu}$ çalışmanın konusu olan düşey kontrol ağ 1 1154 nokta (BM), 32 güzergah (line) ve 11 kapalı looptan oluşmakta olup yaklaş1k 7434 $\mathrm{km}$ uzunluğundadır.

Tablo 2. Nivelman ölçülerine getirilen düzeltme değerleri (mm)

\begin{tabular}{|c|c|c|c|c|}
\hline $\begin{array}{c}\text { Ölçülere getirilen } \\
\text { düz. }\end{array}$ & Min & $\operatorname{Max}$ & $\begin{array}{c}\text { St. } \\
\text { sapma }\end{array}$ & Ort. \\
\hline $\begin{array}{l}\text { Mira ölçek ve } \\
\text { sıcaklık düz. }\end{array}$ & -0.65 & 0.96 & 0.07 & 0.00 \\
\hline Küresellik düz. & -0.10 & 0.10 & 0.02 & 0.00 \\
\hline $\begin{array}{l}\text { Astronomic } \\
\text { düz. }\end{array}$ & -0.25 & 0.04 & 0.04 & 0.04 \\
\hline $\begin{array}{l}\text { Refraksiyon } \\
\text { düz. }\end{array}$ & -7.9 & 9.7 & 1.08 & 0.00 \\
\hline $\begin{array}{l}\text { Güzergah } \\
\text { kapanma } \\
\text { hataları } *\end{array}$ & -8.8 & 7.7 & 1.7 & -0.46 \\
\hline
\end{tabular}

Bütün looplar Tablo 1 de verilmiş olan sınır değerlerin altında kapanmıştır. Tüm ağ için sistematik hata analizi yapılmış, Lallemand formüllerine göre her güzergah için rastlantısal, sistematik ve toplam hatalar hesaplanmış ve sirası ile $0.65 \mathrm{~mm}, 0.18 \mathrm{~mm}$ ve $0.69 \mathrm{~mm}$ olarak hesaplanmıştır. Ortalama sistematik hata $\pm 0.20 \mathrm{~mm} / \mathrm{km}$ olarak hesaplanmıştır. Ağın nihai dengelemesi yukarıda açıklanan nedenden dolayı yapılmamıştır.

\section{SONUC}

Bilindiği gibi ülkemizde Türkiye Ulusal Düşey Kontrol Ağ1 (TUDKA) tesis çalışmaları 1936 yılında Antalya mareograf ağının kurulması ile başlanmış (Şerbetci, 1992), 19702002 yılları arasında yaklaşık 26000 noktalı $30000 \mathrm{~km}$ uzunluğunda tesis edilerek ölçülmüştür. TUDKA noktalarının büyük bir kısmının ( $\%$ 63) yol genişletme çalışmaları ve altyapı çalışmaları sonucu tahrip olduğu tesbit edilmiştir. Yer noktaları dışında duvar noktalarının da bilinçli ve bilinçsiz olarak tahrip edildiği saptanmıştır. Ülkemizde 5000 üzerinde GNSS alıcis1 kullanılmakta olup mühendislik projelerinin büyük bir kısmı GNSS ölçüleri ile yapılmaktadır. Bugüne kadar yeterli hassasiyette geoit modeli üretilememiş ve mevcut DKA noktaları ile $\mathrm{cm}$ duyarlıkta geoid modeli üretmek mümkün değildir. Mevcut durumda kullanıcıların elde etmiş oldukları geoit ondülasyon değerleri büyük 
oranda farklılıklar yaratmaktadır. Bu durumda üç seçenek ortaya çıkmaktadır. Bunlar; nevcut nivelman noktalarının yenilenmesi, geoidin iyileştirilerek bazı nivelman noktalarının yenilenmesi veya sadece geoidin iyileştirilerek düşey datum olarak kullanılmasıdır. Geçen süreç içerisinde yapılan toplantılarda nivelman ağının

\section{TEŞEKKÜR}

20132015 y1lları arasında Proje Yöneticisi olarak görev aldığım Region 3 ve Region 4 projelerinde Proje Danışmanı olarak görev yapan Dr. Coşkun Demir Bey'e, yüklenici firma STIT ve TAMAYA Gruplarına teşekkür ederim.

\section{KAYNAKCA}

Ayhan, M.E., Demir, C. (1992). Türkiye Ulusal Düşey Kontrol (Nivelman) Ağı-1992 (TUDKA-92). Harita Dergisi, Sayı 109

Demir, C., Cingöz, A., Şerbetci, M. (1992) Ülke Temel Jeodezik Ağın Tarihçesi, Nirengi, Nivelman ve Gravite Ağları, Harita ve Kadastro Mühendisliği, Say1: 72 Ankara

Demir, C. (1999). Türkiye Ulusal Düşey Kontrol Ağı-1999 (TUDKA-99). HGK İç Rapor No: Jeofniv-02-1999, Jeodezi Dairesi Başkanlığı, Ankara.

Kılıçoğlu,A., Direnç, A., Yıldız, H., Bölme, M., Aktuğ, B., Simav, M., Lenk O. (2011). Regional gravimetric quasigeoid model and transformation surface to national height system for Turkey (THG09), Studia Geophysica et Geodaetica, 55, 557578.

Simav, M., ve dig. (2015). Türkiye Yükseklik Sisteminin Modernizasyonu ve Gravite Altyapısının İyileştirilmesi Projesi TMMOB Harita ve Kadastro Mühendisleri Odas1, 15.Türkiye Harita Bilimsel ve Teknik Kurultay1, 2528 Mart 2015, Ankara.

Simith, C. L. (2010). Bech Mark reset procedures, National Geodetic Survey, Silver Spring MD 20910, September,2010

Demir, C. ve Yaprak, S. (2016). Suudi Arabistan Hassas nivelman Ağı projesi Region 3 sonuç raporu.

Şerbetci, M., (1992). Ülke Temel Jeodezik Ağın Tarihçesi, Nirengi, Nivelman ve Gravite Ağları, Harita ve Kadastro Mühendisliği, Sayı: 72 Ankara

Yaprak, S., Demir, C., (2015). Monumentation and Geodetic Precise Leveling Observation for BMs KSA Geodetic Leveling Network yenilenmesine karar verilmiştir. $\mathrm{Bu}$ çalışma karar verilmiş olan DKA yenileme çalışmalarına ilave bir katkı sağlayabileceği düşüncesi ile hazırlanmıştır.

Region 3 Final Report. STIT and TAMATA Group. KSA.

http://www.hgk.msb.gov.tr/images/jeodezifaaliyetle r/d5a4eb6752402a7.pdf

https://www.ngs.noaa.gov/FGCS/tech_pub/1984stds-specs-geodetic-control-networks.htm

http://www.fulcrumapp.com/apps/categories/engine ering/

https://www.ngs.noaa.gov/PC_PROD/pc_prod.sht ml\#WinDesc

https://www.ngs.noaa.gov/FGCS/tech_pub/1984std s-specs-geodetic-control-networks.htm

https://www.lantmateriet.se/globalassets/kartoroch-geografisk-information/gps-ochmatning/geodesi/rapporter_publikationer/rap porter/lantmaterirapport 2014 2.pdf

https://www.ngs.noaa.gov/PC_PROD/pc_prod.sht $\underline{\text { ml\#Translev }}$ 